\title{
RETRACTED ARTICLE: Al driven feature extraction model for chest cavity spectrum signal visualization
}

\author{
Haitao Niu ${ }^{1}$. Jihua $\mathrm{Gu}^{2}$
}

Received: 21 December 2020 / Accepted: 4 April 2021 / Published online: 30 April 2021

(c) The Author(s), under exclusive licence to Springer Science+Business Media, LLC, part of Springer Nature 2022

The Editor-in-Chief and the publisher have retracted this article. The article was submitted to be part of a guestedited issue. An investigation by the publisher found a number of articles, including this one, with a number of concerns, including but not limited to compromised editorial handling and peer review process, inappropriate or irrelevant references or not being in scope of the journal or guest-edited issue. Based on the investigation's findings the Editor-inChief therefore no longer has confidence in the results and conclusions of this article. The author Haitao Niu has not responded $* *$ to correspondence regarding this retraction. The Publisher has not been able to obtain a current email address for author Jihua $\mathrm{Gu}$.
The online version of this article contains the full text of the retracted article as Supplementary Information.

Supplementary Information The online version contains supplementary material available at https://doi.org/10.1007/s10772-021-09844-w.

Publisher's Note Springer Nature remains neutral with regard to jurisdictional claims in published maps and institutional affiliations.

Springer Nature or its licensor (e.g. a society or other partner) holds exclusive rights to this article under a publishing agreement with the author(s) or other rightsholder(s); author self-archiving of the accepted manuscript version of this article is solely governed by the terms of such publishing agreement and applicable law.
Haitao Niu

niuhaitaofeilong@126.com

1 School of Physical Science and Technology, Soochow University, Suzhou 215006, China

2 School of Optoelectronic Science and Engineering, Soochow University, Suzhou 215006, China 